\title{
Electrochemical Sensor for the Determination of Adrenaline in Presence of Acetaminophen at Poly (Alanine) Modified Carbon Paste Electrode: A Cyclic Voltammetric Study
}

\author{
Harisha KV ${ }^{1}$, Swamy BEK ${ }^{2 *}$, Jayadevappa H $^{1}$ and Ganesh PS ${ }^{2}$
}

${ }^{1}$ Department of Chemistry, Sahyadri Science College, Shimoga, Karnataka, India

${ }^{2}$ Department of PG Studies and Research in Industrial Chemistry, Kuvempu University, JnanaSahyadri, Shankaraghatta, Shimoga, Karnataka, India

\begin{abstract}
The electropolymerisation of DL-alanine was carried out at the surface of carbon paste electrode by cyclic voltammetric (CV) technique. The fabricated electrode was used for the electrocatalysis of adrenaline at neutral $\mathrm{pH}$. The key parameters like influence of scan rate and concentration reveals the adsorption controlled process. The lower limit of detection was calculated to be $28.0 \mathrm{nM}$ in the linear range of 10 to $60 \mu \mathrm{M}$ by CV technique. Further, the poly (alanine) modified carbon paste electrode can be used for the selective determination of adrenaline in presence of acetaminophen. Overall, the fabricated electrode can be used as a promising analytical sensor in the determination of adrenaline in pharmaceutical and biological samples.
\end{abstract}

Keywords: Electropolymerisation; Adrenaline; Acetaminophen; DL-alanine; Electrocatalytic activity

\section{Introduction}

Adrenaline (AD) is one of the neurotransmitter catecholamine found in the mammalian central nervous system; exist in the form of large organic cations in the nervous tissue and biological body fluid [1]. It serves as a neurotransmitter for conveying the nerve pulse to different organs. Adrenaline is sympathomimetic drug widely used for the treatment of hypertension, cardiac arrest, myocardial infection and cardiac surgery in clinics. It also used to stimulate heartbeat and to treat emphysema, bronchitis, bronchial asthma and other allergic conditions, as well as in the treatment of the eye disease, glaucoma [2]. Variation in the concentration of AD leads to severe disease. Therefore, sensitive determination of adrenaline concentration has an important significance to medicine, nerve psychology and life science [3]. Several methods have been reported for the determination of adrenaline such as high performance liquid chromatography [4-6], fluorometry [7-9] chemiluminescence [10,11], capillary electrophoresis [12] and spectrophotometry [13]. However, such methods are quite complicated since some of these methods need derivatization or combination with various detection methods. They also have low sensitivity and specificity. Some reports have shown the electrochemical response of adrenaline on different kinds of electrodes such as poly (osmiumoxide/ hexacyanoruthenate) film modified CPE [14], poly (eriochrome black T) film modified GCE [15], poly (1-Methylpyrrole) modified glassy carbon electrode which exhibited good electro catalytic activity for the detection of adrenaline [3].

Acetaminophen or paracetamol (AP) is widely used as an antipyretic and analgesic drug. It is an effective and safe analgesic agent used for the relief of mild to moderate pain associated with headache, backache, arthritis and postoperative pain [16]. It is also used for the reduction of fever caused by viral and bacterial origin. It relieves pain and fever by inhibiting prostaglandin's synthesis in the central nervous system and sedating hypothalamic heat-regulating center $[17,18]$. Generally, acetaminophen does not exhibit any harmful side effects. However, hypersensitivity or over dosage of AP leads to the formation of some liver and nephrotoxic metabolites. Moreover, the hydrolytic degradation product of acetaminophen is 4 -aminophenol which can cause fatal hepatotoxicity and nephrotoxicity. This species can be found in pharmaceutical preparations as a degradation product of acetaminophen or as a synthetic intermediate [19]. Acetaminophen drug is available in different dosage forms of tablets, capsules, suspensions. Thus development of simple, sensitive and accurate analytical methods for determination of acetaminophen in pharmaceutical products and human plasma is of great importance [20]. Many analytical methods are reported to determine the acetaminophen concentration such as spectrophotometry [21], high performance liquid chromatography [22], and voltammetry [23]. These techniques are generally expensive and time-consuming. There are several number of modified electrodes like titanium oxide nanoparticle $\mathrm{MPE}$, nafion/ $/ \mathrm{TiO}_{2}$ - graphene modified GPE, $\mathrm{ZrO}_{2}$ nano particle modified CPE, single walled carbon nanotube MCPE have been reported for the determination of acetaminophen by using voltammetric techniques [20,24-26].

Therefore, there is a great interest in the development of new analytical methods for the simultaneous determination of pharmaceuticals without the necessity of a previous separation of the sample components, besides being rapid and with low cost. To overcome these limitations, electrochemical methods such as voltammetric ones were extensively used because of simplicity, rapid response, excellent reproducibility, good stability, low cost and low detection limit [27-29].

Now a day's carbon paste electrode was very much attracted towards the determination of biologically active molecules because of the easy preparation of modified electrode, renewability, low background current and fast response. However, Polymer modified

*Corresponding author: Kumara Swamy BE, Department of PG Studies and Research in Industrial Chemistry, Kuvempu University, JnanaSahyadri, Shankaraghatta-577451, Shimoga, Karnataka, India, Tel: +9182822562251; Fax +91 8282-256255; E-mail: kumaraswamy21@yahoo.com

Received November 01, 2016; Accepted November 21, 2016; Published November 30, 2016

Citation: Harisha KV, Swamy BEK, Jayadevappa H, Ganesh PS (2016) Electrochemical Sensor for the Determination of Adrenaline in Presence of Acetaminophen at Poly (Alanine) Modified Carbon Paste Electrode: A Cyclic Voltammetric Study. J Biosens Bioelectron 7: 230. doi: 10.4172/2155-6210.1000230

Copyright: (c) 2016 Harisha KV, et al. This is an open-access article distributed under the terms of the Creative Commons Attribution License, which permits unrestricted use, distribution, and reproduction in any medium, provided the original author and source are credited. 
Citation: Harisha KV, Swamy BEK, Jayadevappa H, Ganesh PS (2016) Electrochemical Sensor for the Determination of Adrenaline in Presence of Acetaminophen at Poly (Alanine) Modified Carbon Paste Electrode: A Cyclic Voltammetric Study. J Biosens Bioelectron 7: 230. doi: $10.4172 / 2155-6210.1000230$

Page 2 of 6

electrodes (PMEs) have received great attention in recent years. As the polymer film which is deposited onto the surface of the electrode by electropolymerisation have good stability, reproducibility, more active sites, homogeneity and strong adherence to the electrode surface. Electropolymerisation is a good approach to immobilize polymers to prepare PMEs [30,31].

The present work describes an electropolymerisation of DLalanine on the surface of carbon paste electrode by cyclic voltammetric technique. On the basis of its different electrochemical behaviour poly (alanine) MCPE was used for the detection of electroactive molecules [32-34]. In the continuation of our study, we proposed convenient method for the selective and sensitive detection of adrenaline in the presence of acetaminophen, which has a significant attraction in biological and chemical fields.

\section{Experimental Part}

\section{Apparatus and reagents}

Cyclic voltammetry $(\mathrm{CV})$ and differential pulse voltammetry (DPV) were performed in an analytical system model CHI-660c (CH Instruments, Electrochemical workstation) potentiostat. A conventional three electrode electrochemical cell contained a saturated calomel electrode (SCE) as a reference, platinum wire as counter electrode and the working electrode was either bare carbon paste electrode (BCPE) or poly(alanine) modified carbon paste electrode (MCPE). The $\mathrm{pH}$ values were measured and calibrated using a digital pH meter MK VI (Systronics).

Adrenaline and DL-alanine samples were purchased from Himedia; acetaminophen was purchased from Sigma Aldrich. A stock solution of AD prepared with $0.1 \mathrm{M}$ Perchloric acid. Graphite powder (50 $\mathrm{m}$ average size) was purchased from Loba and silicon oil (as binding agent) was purchased from Himedia. All chemicals were of analytical grade. The chemicals for the preparation of buffer solution were purchased from Merck. Thephosphate buffer solution (PBS) was prepared by mixing standard stock solutions of $0.2 \mathrm{M} \mathrm{NaH}_{2} \mathrm{PO}_{4} \mathrm{H}_{2} \mathrm{O}$ and $0.2 \mathrm{M} \mathrm{Na}_{2} \mathrm{HPO}_{4}$. Freshly prepared solutions of AD, AP were used for analysis. All the aqueous solutions were prepared using double distilled water.

\section{Preparation of working electrode}

The bare carbon paste electrode (BCPE) was prepared according to the previous report $[32,34]$. Surface modification of the CPE was carried out by placing $1 \mathrm{mM} \mathrm{DL}$-alanine solution in an electrochemical cell containing $0.2 \mathrm{M}$ PBS of $\mathrm{pH} 7.0$ by potential scanning the electrode between the potential window -0.6 to $1.4 \mathrm{Vs}^{-1}$ at the scan rate $50 \mathrm{mVs}^{-1}$ for 10 cycles. After electropolymerisation the modified electrode was rinsed in double distilled water and stored in $0.2 \mathrm{M} \mathrm{PBS}(\mathrm{pH}$ 7.0) until use.

\section{Results and Discussions}

\section{Optimization of experimental conditions}

The electropolymerisation of alanine was achieved by the formation of ultra-thin film that grew between -0.6 to $1.4 \mathrm{Vs}^{-1}$ at the scan rate of $50 \mathrm{mVs}^{-1}$ as shown in Figure 1. The electrochemical response of 0.1 $\mathrm{mM}$ adrenaline in pH 7.0 PBS at different cyclised (5, 10, 15 \& 20) poly (alanine) MCPE was shown in Figure 2A. The plot of anodic peak current (Ipa) obtained for the oxidation of adrenaline versus number of polymerised cycles was plotted. The thickness of the electroactive layer directly affects the electrocatalytic activity of the fabricated electrode. As shown in the obtained results, maximum current

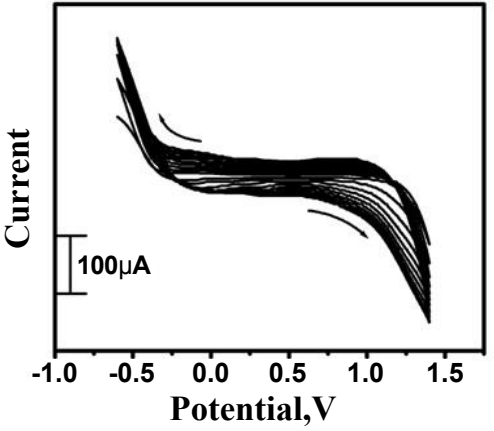

Figure 1: Cyclic voltammograms for the electrochemical polymerization of 1.0 $\mathrm{mM}$ DL-alanine in $0.2 \mathrm{M} \mathrm{PBS}(\mathrm{pH} 7.0)$ at BCPE with the scan rate $50 \mathrm{mVs}^{-1}$.

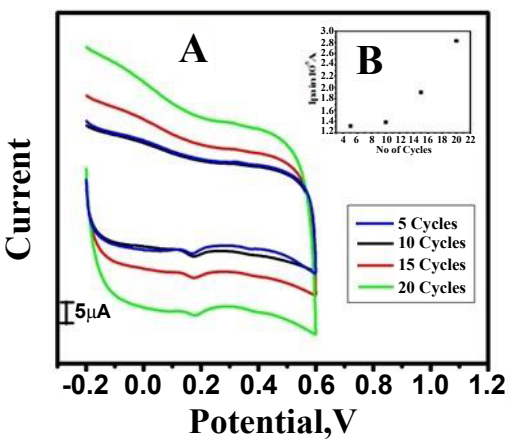

Figure 2: (A) Cyclic voltammogramsrecorded for $0.1 \mathrm{~m}$ Madrenaline at different cyclised poly (alanine) MCPE $(5,10,15$, and 20) in PBS at pH 7.0 (B) Plot of anodic peak current versus number of polymerisation cycles.

response is obtained for 20 multiple cycles. However, a better catalytic performance was observed for the electrode which was modified by ten consecutive cycle scans. Therefore, the poly (alanine) MCPE was fabricated by considering all the above mentioned parameters. The probable electropolymerisation mechanism of alanine was described in scheme 1 (Figures 1 and 2 and Scheme 1).

\section{Electrochemical investigation potassium ferrocyanide at poly (alanine) MCPE}

In order to study the performance of the poly (alanine) MCPE potassium ferrocyanide was selected as an electrochemical probe. Figure 3 shows electrochemical response of potassium ferrocyanide at BCPE (dashed line) and poly (alanine) MCPE (solid line) in $1 \mathrm{M}$ $\mathrm{KCl}$ as a supporting electrolyte at the scan rate of $50 \mathrm{mVs}^{-1}$. A pair of redox peaks observed for BCPE and with the modified CPE. The poly (alanine) MCPE shows electrochemical property with lower the peak potential difference $(\Delta \mathrm{Ep})$. As $\Delta \mathrm{Ep}$ is a function of electron transferrate, lower the $\Delta \mathrm{Ep}$ higher will be the electron transfer rate. The result shows a dramatic change in the voltammetric response at fabricated electrode (Figure 3) [33].

\section{Electrochemical behaviour of adrenaline at the poly (alanine) MCPE}

Figure 4 shows the cyclic voltammograms obtained for the electrochemical response of $0.1 \mathrm{mM} \mathrm{AD}$ at poly (alanine) MCPE (solid line) and BCPE (dashed line) in $0.2 \mathrm{M}$ PBS of $\mathrm{pH} 7.0$ recorded at the sweep rate of $50 \mathrm{mVs}^{-1}$. At the BCPE the anodic peak potential was found to be $0.216 \mathrm{~V}$ (versus SCE). However, at poly(alanine) MCPE 
Citation: Harisha KV, Swamy BEK, Jayadevappa H, Ganesh PS (2016) Electrochemical Sensor for the Determination of Adrenaline in Presence of Acetaminophen at Poly (Alanine) Modified Carbon Paste Electrode: A Cyclic Voltammetric Study. J Biosens Bioelectron 7: 230. doi: $10.4172 / 2155-6210.1000230$

Page 3 of 6

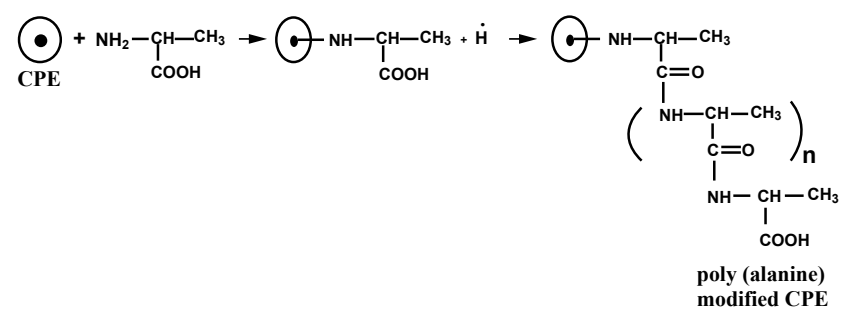

Scheme 1: Probable electropolymerisation mechanism of alanine on the surface of carbon paste electrode.

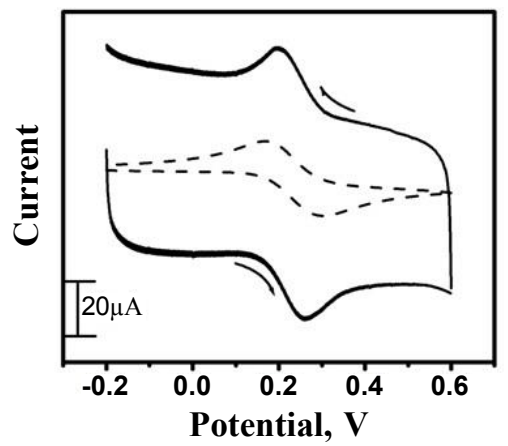

Figure 3: Cyclic voltammograms for electrochemical response of $1 \mathrm{mM}$ potassium ferrocyanide at BCPE (dashed line) and poly (alanine) MCPE (solid line) in $1 \mathrm{M} \mathrm{KCl}$ solution at the scan rate $50 \mathrm{mVs}^{-1}$.

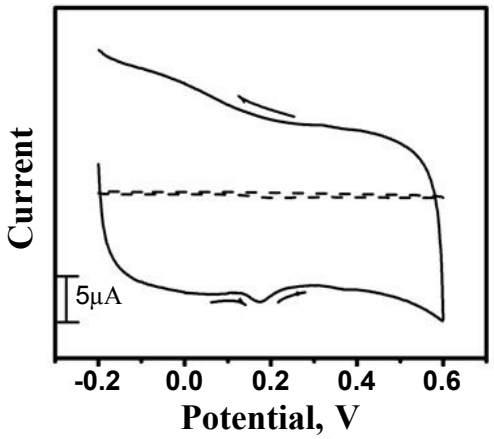

Figure 4: Cyclic voltammograms obtained for the oxidation of $0.1 \mathrm{~m} \mathrm{MAD}$ at poly (alanine) MCPE (solid line) and BCPE (dashed line) in 0.2 M PBS (pH7.0) scan rate $50 \mathrm{mVs}^{-1}$

the anodic peak potential was found by $0.174 \mathrm{~V}$ with increase in anodic peak current. The poly(alanine) MCPE shows enhancement in anodic peak current with minimization in the over potential as compared to BCPE. The voltammetric refinement confirms the poly (alanine) MCPE has significant electro capability towards the oxidation of adrenaline (Figure 4) [34-40].

\section{The effect of scan rate}

The electrochemical response of $0.1 \mathrm{mM}$ adrenaline at poly (alanine) MCPE was investigated at different scan rates from 50-300 $\mathrm{mVs}^{-1}$. The poly (alanine) MCPE showed increase in the peak currents with increase in the scan rates with a small shift in the oxidation peak potential towards more positive potential as shown in Figure 5A. This result is in accordance with Randles-Sevick's equation, confirming the kinetic limitation of the electrochemical process. The plot of anodic peak current (Ipa) versus scan rate $(v)$ gives almost straight line (Figure 5) with linear regression equation of $\operatorname{Ipa}(\mu \mathrm{A})=0.3089\left(v \mathrm{Vs}^{-1}\right)+8.836$. The correlation coefficient was $r^{2}=0.9989$; the result indicates the electrochemical oxidation of adrenaline on the surface of poly (alanine) MCPE was adsorption-controlled process (Figure 5) [3].

\section{The effect of concentration on poly (alanine) MCPE}

The effect of varying concentration of adrenaline was studied at poly (alanine) MCPE in $0.2 \mathrm{M}$ PBS pH 7.0 at a scan rate of $50 \mathrm{mVs}^{-1}$ as shown in the Figure 6A. It is clearly observed that, anodic peak current of adrenaline was increased as a result of increased concentration of adrenaline in the range 10 to $60 \mu \mathrm{M}$. The plot of Ipa versus concentration of AD shows two linearity in the graph. For the first linearity $\left(r^{2}=0.9977\right)$ the correlation coefficient was $\operatorname{Ipa}(\mu \mathrm{A})=24.65\left(\mathrm{Co} 10^{-4} \mathrm{M} / \mathrm{L}\right)+14.54$. And for second linearity it was expressed to be $\left(\mathrm{r}^{2}=0.9933\right) \mathrm{Ipa}(\mu \mathrm{A})=15.4(\mathrm{Co}$ $\left.10^{-4} \mathrm{M} / \mathrm{L}\right)+17.826$. The limit of detection and limit of quantification was calculated by using equation (1) and (2).

\section{$\mathrm{LOD}=3 \mathrm{~S} / \mathrm{M}$ \\ $\mathrm{LOQ}=10 \mathrm{~S} / \mathrm{M}$}

Where $\mathrm{S}$ is the standard deviation and $\mathrm{M}$ is the slope of calibration plot. The limit of detection and limit of quantification for first linear range (a) was found to be $28.0 \mathrm{nM}$ and $94.4 \mathrm{nM}$, for second linear range (b) was found to be $49.0 \mathrm{nM}$ and $164.0 \mathrm{nM}$. The proposed method exhibited relatively lower detection limit as compared with the early reports as shown in Table 1 (Figure 6 and Table 1).

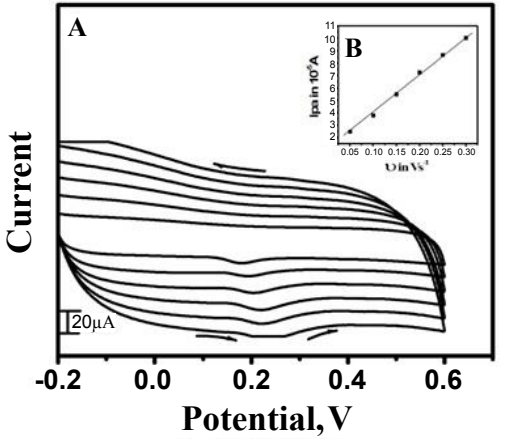

Figure 5: (A) Cyclic voltammograms of 0.1mMA Don the poly (alanine) MCPE at different scan rates $\left(50-300 \mathrm{mVs}^{-1}\right)$ in $0.2 \mathrm{M}$ PBS $(\mathrm{pH} 7.0)$ (B) The plot of the anodic peak current versus scan rate.

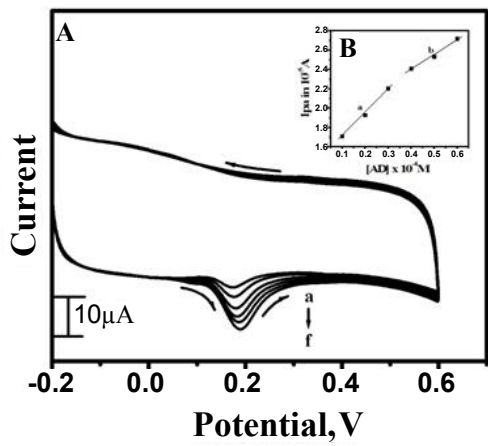

Figure 6: (A) Cyclic voltammograms of different concentration of $A D$ at poly (alanine) MCPE in 0.2 M PBS (pH 7.0) in the linear range of $10-60 \mu \mathrm{M}$ at scan rates $50 \mathrm{mVs}^{-1}(B)$ Plot of anodic peak current versus concentration of AD. 
Citation: Harisha KV, Swamy BEK, Jayadevappa H, Ganesh PS (2016) Electrochemical Sensor for the Determination of Adrenaline in Presence of Acetaminophen at Poly (Alanine) Modified Carbon Paste Electrode: A Cyclic Voltammetric Study. J Biosens Bioelectron 7: 230. doi: $10.4172 / 2155-6210.1000230$

Page 4 of 6

\begin{tabular}{|c|c|c|c|c|}
\hline Modified Electrodes & Linear Range $(\mu \mathrm{M})$ & Detection Limit $(\mu \mathrm{M})$ & Method & References \\
\hline Poly (1-Methylpyrrole) M GCE & $0.1-0.8$ & 0.56 & CV & [2] \\
\hline Pen SAM-MAuE & $0.1-100$ & 0.1 & CV & [35] \\
\hline P (1-methyl pyyrrole) GCE & $0.75-200$ & 0.168 & SWV & [36] \\
\hline $\mathrm{P}$ (taurine) ME & $2-600$ & 0.3 & DPV & [37] \\
\hline Poly (caffeinic acid) MCPE & $2-300$ & 0.6 & $\mathrm{CV}$ & [38] \\
\hline TTABMCPE & $0.15-30$ & 0.12 & DPV & [39] \\
\hline Poly (alanine) Modified CPE & $0.01-0.06$ & $\begin{array}{l}a-28 n M \\
b-49 n M\end{array}$ & CV & This Work \\
\hline
\end{tabular}

Table 1: Comparison of limit of detection with different modified electrodes and poly (alanine) modified CPE.

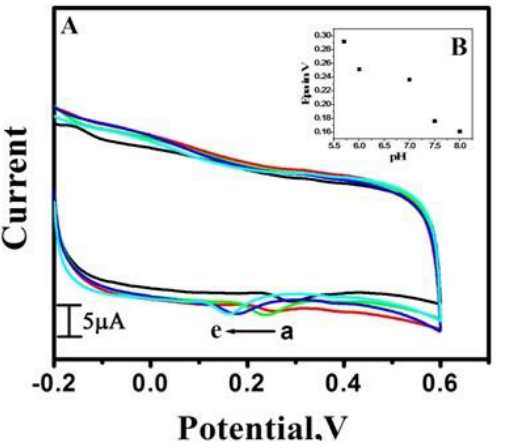

Figure 7: (A) Cyclic voltammograms obtained for oxidation of $0.1 \mathrm{~m}$ MAD at poly (alanine) MCPE in $0.2 \mathrm{M}$ PBS of different $\mathrm{pH}$ values (a-e: 5.7, 6.0, 7.0, 7.5 and $8.0)$ at scan rate $50 \mathrm{mVs}^{-1}(\mathbf{B})$ The plot of the anodic peak potential versus $\mathrm{pH}$.<smiles>CN(CC1C=CC=CC1=O)CC(O)c1ccc(O)c(O)c1</smiles>

Adrenaline Adrenoquinone

Scheme 2: Oxidation of mechanism of adrenaline and paracetamol.

\section{Influence of $\mathrm{pH}$ on poly (alanine) $\mathrm{MCPE}$}

The effect of $\mathrm{pH}$ on the oxidation of adrenaline at poly (alanine) $\mathrm{MCPE}$ was investigated by varying the $\mathrm{pH}$ of the $0.2 \mathrm{M}$ PBS. As the $\mathrm{pH}$ gradually increases from 5.7 to 7.0 the anodic peak potential shifts to more negative potential as shown in Figure 7A. The graph of anodic peak potential with $\mathrm{pH}$ of the buffer solution gives a slope value of 53.0 $\mathrm{mV} / \mathrm{pH}$. This is in accordance with the Nernst equation. Therefore the oxidation of $\mathrm{AD}$ at poly (alanine) MCPE surface involves the transfer of equal number of protons and electrons in the oxidation mechanism [40-41]. The oxidation mechanism of AD was depicted in scheme 2 (Figure 7 and Scheme 2).

\section{Simultaneous determination of $\mathrm{AD}$ in the presence of $\mathrm{AP}$ at poly (alanine) MCPE}

Figure 8 shows the cyclic voltammograms of simultaneous determination of $0.1 \mathrm{mM} \mathrm{AD}$ and $0.1 \mathrm{mM} \mathrm{AP}$ at $\mathrm{pH} 7.0 \mathrm{PBS}$. The voltammogram obtained for the mixture of sample at BCPE was less sensible (dotted line) the oxidation potentials of $\mathrm{AD}$ and $\mathrm{AP}$ was located at $0.226 \mathrm{~V}$ and $0.384 \mathrm{~V}$ respectively. On the other hand, at poly (alanine) MCPE (solid line) shows well-defined oxidation peaks observed at $0.174 \mathrm{~V}$ and $0.367 \mathrm{~V}$ for $\mathrm{AD}$ and $\mathrm{AP}$ respectively. The peak to peak separation was $0.193 \mathrm{~V}$; this indicates that poly (alanine) MCPE act as a good electrochemical sensor for the determination of $\mathrm{AD}$ and AP present in the binary mixture.

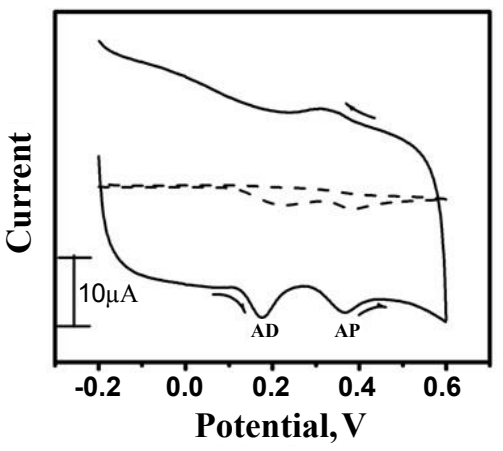

Figure 8: Cyclic voltammograms obtained for oxidation of $0.1 \mathrm{mM} \mathrm{AD}$ and 0.1 $\mathrm{mM}$ AP in 0.2 M PBS ( $\mathrm{pH} 7.0$ ) at BCPE (dashed line) and poly (alanine) MCPE (solid line) at scan rate of $50 \mathrm{mVs}^{-1}$.

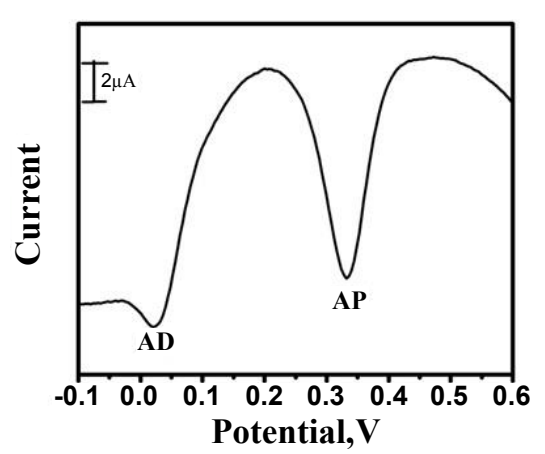

Figure 9: Differential pulse voltammogram recordings for $0.1 \mathrm{mM} A D$ and 0.3 $\mathrm{mM} \mathrm{AP}$ at poly (alanine) MCPE in 0.2M PBS at pH 7.0.

Differential pulse voltammograms were recorded due its higher current sensitivity and the determination of $\mathrm{AD}$ and $\mathrm{AP}$ at poly (alanine) MCPE in $0.2 \mathrm{M} \mathrm{PBS}$ of $\mathrm{pH} 7.0$ was conducted as shown in the Figure 9. At poly (alanine) MCPE a well resolved oxidation peaks were located at $0.015 \mathrm{~V}$ for $\mathrm{AD}$ and $0.331 \mathrm{~V}$ for $\mathrm{AP}$. Therefore a simultaneous separation of $\mathrm{AD}$ and $\mathrm{AP}$ was observed at poly (alanine) MCPE.

The electrochemical study was conducted by varying the concentration of $\mathrm{AD}$ constant and varied the concentration of AP by $\mathrm{DPV}$ technique. After variation of $\mathrm{AP}$ and $\mathrm{AD}$, this modified electrode is more sensitive for $\mathrm{AD}$ compared with $\mathrm{AP}$. This result suggests the oxidation of both the analytes occurs independently and effectively at the poly (alanine) MCPE (Figures 8-10).

\section{Conclusion}

The present study demonstrates electropolymerisation of 
Citation: Harisha KV, Swamy BEK, Jayadevappa H, Ganesh PS (2016) Electrochemical Sensor for the Determination of Adrenaline in Presence of Acetaminophen at Poly (Alanine) Modified Carbon Paste Electrode: A Cyclic Voltammetric Study. J Biosens Bioelectron 7: 230. doi: $10.4172 / 2155-6210.1000230$

Page 5 of 6

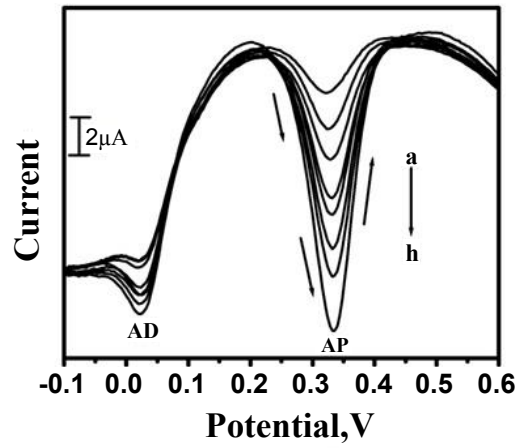

Figure 10: Differential pulse voltammogram recordings for varying concentration of AP (a-h: 0.1-0.6 $\mathrm{mM}$ ) in presence of $0.1 \mathrm{mM} \mathrm{AD}$ at poly (alanine) MCPE.

alanine on the surface of BCPE and exploring its advantages for the electrochemical determination of $\mathrm{AD}$ and $\mathrm{AP}$. The result shows poly(alanine) MCPE not only exhibited strong electrocatalytic activity towards the oxidation of $\mathrm{AD}$ and $\mathrm{AP}$, it also increased the selectivity of the separation. Because of its high electrocatalytic behaviour, good selectivity in separation, sensitivity in measurement, reproducibility in result with the advantage of easy preparation and convenient surface modification, the poly (alanine) MCPE was very useful in the development of sensor for the determination of neuroactive adrenaline in the presence of interfering compound acetaminophen.

\section{References}

1. Sun YX, Wang SF, Zhang XH, Huang YF (2006) Simultaneous determination of epinephrine and ascorbic acid at the electrochemical sensor of triazole SAM modified gold electrode. Sens Actuators B 113: 156-161.

2. Aslanoglu M, Kutluay A, Karabulut S, Abbasoglu S (2008) Voltammetric Determination of Adrenaline Using a Poly(1-Methylpyrrole) Modified Glassy Carbon Electrode. J Chin Chem Soc 55: 794-800.

3. Ardakania MM, Beitollahi $\mathrm{H}$, Mohsenia MAS, Benvidia $A$, Naeimib $H$, et al. (2010) Simultaneous determination of epinephrine and acetaminophen concentrations using a novel carbon paste electrode prepared with $2,2^{\prime}-[1,2$ but anediylbis(nitriloethylidyne)]-bis-hydroquinone and $\mathrm{TiO}_{2}$ nanoparticles. Colloids SurfB: Biointerfaces 76: 82-87.

4. Vaarman A, Kask A, Maeorg U (2002) Novel and sensitive high-performance liquid chromatographic method based on electrochemical coulometric array detection for simultaneous determination of catecholamines, kynurenine and indole derivatives of tryptophan. J Chromatogr B 769: 145-153.

5. Zhang W, He L,Gu Y, Liu X, Jiang S (2003) Effect of lonic Liquids as Mobile Phase Additives on Retention of Catecholamines in Reversed-Phase HighPerformance Liquid Chromatography. J Anal Lett 36: 827-838.

6. Li H, Luo W, Hu X (1999) Determination of enantiomeric purity for epinephrine by high performance liquid chromatography. J Chromatogr 17: 403-405.

7. Yang JH, Zhang GL, Wu X, Huang F, Li CG, et al. (1998) Fluorimetric determination of epinephrine with o-phenylenediamine. J Anal Chim Acta 363 105-110.

8. Salem AA, Barsoum BN, Izake EL (1993) Spectrophotometric and Fluorimetric Determination of Catecholamines. J Ana Lett 26: 281-294.

9. Zhu XL, Shaw PN, Barrett DA (2003) Catecholamines derivatized with 4-fluoro7-nitro-2,1,3-benzoxadiazole: characterization of chemical structure and fluorescence properties. J Anal Chim Acta 478: 259-269.

10. Zheng XW, Guo ZH, Zhang Z (2001) Flow injection electrogenerated chemiluminescence determination of epinephrine using luminol. J Anal Chim Acta 441: 81-86

11. Yao H, Sun YY, Lin XH, Chen JH, Huang LY (2006) Flow-injection chemiluminescence determination of catacholamines based on their enhancing effects on the luminol-potassium periodate system. Luminescence 21: 112-117.
12. Philip BM, Andrea RK, Alison P, David DYC (1998) Quantitative assay for epinephrine in dental anaesthetic solutions by capillary electrophoresis. Analyst 123: 1461-1463.

13. Nagaraja $P$, Vasantha RA, Sunitha KR (2001) A sensitive and selective spectrophotometric estimation of catachol derivatives in pharmacauetical preperations. Talanta 55: 1039-1046.

14. Chen SM, Liao CJ, Vasantha VS (2006) Preparations and electro catalytic properties of osmium oxide/hexacyanoruthenate films modified electrodes for catacholamines and sulphur oxoanions. J Electroanal Chem 589: 15-23.

15. Yao H, Sun Y, Lin X, Tang Y, Liu A, et al. (2007) Selective determination of epinephrine in the presence of ascorbic acid and uric acid by electrocatalytic oxidation of poly(eriochrome Black-T) film-modified glassy carbon electrode. Anal Sci 23: 677-682.

16. Carvalho RMD, Freire RS, Rath S, Kubota LT (2004) Effects of EDTA on signal stability during electrochemical detection of acetaminophen. J Pharm Biomed Anal 34: 871-878.

17. Rajendra NG, Sudhanshu PS (2006) Voltammetric determination of paracetamol at $\mathrm{C}_{60}$-modified glassy carbon electrode. Electrochimica Acta 51: 3008-3012.

18. Vishwanath CC, Swamy BEK (2014) Electrochemical Studies of Paracetamo at Poly (Aniline Blue) Modified Carbon Paste Electrode: A Voltammetric Study. Anal Bioanal Electrochemistry 6: 573-582.

19. Yesilada A, Erdogan H, Ertan M (1991) Second derivative spectrophotometric determination of $p$-aminophenolin the presence of paracetamol. J Anal Lett 24 129-138.

20. Yang F, Jin HL, Hai TL, Qin Z (2011) Electrochemical behaviour and voltammetric determination of paracetamol on Nafion/TiO glassy carbon electrode. Colloids Surf B: Biointerfaces 85: 289-292.

21. Khoshayand MR, Abdollahi H, Shariatpanahi M, Saadatfard A, Mohammad A (2008) Simultaneous spectrophotometric determination of paracetamol, ibuprofen and caffeine in pharmacaueticals by chemometric methods. Spectrochim Acta Part A 70: 491-499.

22. Ing-Lorenzini KR, Desmeules JA, Besson M, Veuthey JL, Dayer P, et al (2009) Two-dimentional liquid chromatography ion-trap mass spectrometry for the simultaneous determination of ketorolac enantiomers and paracetamol in human plasma: Application to a pharmacokinetic study. J Chromatog A 1216 3851-3856.

23. Burgot G, Auffret F, Burgot JL (1997) Determination of acetaminophen by thermometric titrimetry. Ana Chim Acta 343: 125-128.

24. Gururaj KJ, Swamy BEK (2013) Electrochemical Synthesis of Titanium Nano Particles at Carbon Paste Electrodes and Its Applications as an Electrochemica Sensor for the Determination of Acetaminophen in Paracetamol Tablet. Soft Nanoscience Letter 3: 20-22.

25. Mohammad MA, Hadi B, Mohammad KA, Fakhradin M, Mohammad A (2010) New strategy for simultaneous and selective voltammetric determination of norepinephrine, acetaminophen and folic acid using $\mathrm{ZrO}_{2}$ nanoparticlesmodified carbon paste electrode. Sens Actuators B 151: 243-249.

26. Biuck H, Mojtaba J, Mohammad HPA (2011) Differential pulse voltammetric simultaneous determination of acetaminophen and ascorbic acid using single-walled carbon nanotube-modified carbon-ceramic electrode. J Anal Biochemistry 411: 167-175.

27. Ganesh PS, Swamy BEK (2015) Simultaneous electro analysis of norepinephrine, ascorbic acid and uric acid using poly (glutamic acid) modified carbon paste electrode. J Electroanal Chem 752: 17-24.

28. Ganesh PS, Swamy BEK (2015) Simultaneous electroanalysis of hydroquinone and catechol at poly(brilliant blue) modified carbon paste electrode: A voltammetric study. J Electroanal Chem 756: 193-200.

29. Ganesh PS, Swamy BEK (2016) Voltammetric resolution of catechol and hydroquinone at eosin $\mathrm{Y}$ film modified carbon paste electrode.J Molecular Liquids 220: 208-215.

30. RaneRF, Blaha CD (1990) Detection of catecholamines in brain tissue: surfacemodified electrodes enabling in vivo investigations of dopamine function. Langmuir 6: 56-65.

31. Ewing AG, Dayton MA, Wightman RM (1981) Pulse Voltammetry with Microvoltammetric Electrodes. J Anal Chem 53: 1842-1847. 
Citation: Harisha KV, Swamy BEK, Jayadevappa H, Ganesh PS (2016) Electrochemical Sensor for the Determination of Adrenaline in Presence of Acetaminophen at Poly (Alanine) Modified Carbon Paste Electrode: A Cyclic Voltammetric Study. J Biosens Bioelectron 7: 230. doi: $10.4172 / 2155-6210.1000230$

32. Harisha KV, Swamy BEK, Jayadevappa H (in press) (2016) Voltammetric resolution of paracetamol in presence of folic acid at poly(alanine) modified carbon paste electrode. J Anal Bioanal Techniques.

33. Gilbert O, Swamy BEK, Chandra U, Sherigara BS (2009) Simultaneous detection of dopamine and ascorbic acid using polyglycine modified carbon paste electrode: A cyclic voltammetric study. J Electro anal Chem 636: 80-85.

34. Harisha KV, Swamy BEK, Jayadevappa H, Vishwanath CC (2015) Voltammetric Determination of Folic acid in presence of Dopamine and Ascorbic Acid at Poly (Alanine) Modified Carbon Paste Electrode. Anal Bioanal Electrochim 7: 454-465.

35. Wang L, Bai J, Huang P, Wang H, Zhang L, et al. (2006) Electrochemical Behavior and Determination of Epinephrine at a Penicillamine Self-assembled Gold Electrode. Int J Electrochem Sci 1: 238-249.

36. Aslanoglu M, Kutluay A, Karabulut S, Abbasoglu S (2008) Voltammetric Determination of Adrenaline Using a Poly(1-Methylpyrrole) Modified Glassy Carbon Electrode. J Chin Chem Soc 55: 794-800.
37. Wang Y, Chen Z (2009) A novel poly (taurine) modified glassy carbon electrode for the simultaneous determination of epinephrine and dopamine. Colloids Surf B 74: 322-327.

38. Ren W, Luo HQ, Li NB (2006) Electrochemical Behavior of Epinephrine at Glassy Carbon Electrode Modified by Electrodeposited Films of Caffeic Acid. Sensors 6: 80-89.

39. Shankar SS, Swamy BEK (2014) Detection of Epinephrine in Presence of Serotonin and Ascorbic Acid by TTAB Modified Carbon Paste Electrode: A Voltammetric Study. Int J Electrochem Sci 9: 1321-1339.

40. Zeng Y, Yang J, Wu K (2008) Electrochemistry and determination of epinephrine using a mesoporous Al-incorporated $\mathrm{SiO}_{2}$ modified electrode. Electrochim Acta 53: $4615-4620$.

41. Chandrashekar BN, Swamy BEK, Ashoka NB, Pandurangachar M (2012) Simultaneous electrochemical determination of epinephrine and uric acid at 1-butyl-4-methyl-pyridinium tetrafluroborate ionic liquid modified carbon paste electrode: A voltammetric study. J Mol Liq 165: 168-172. 